\section{Optimization of Media Constituents for Shoot Regeneration from Leaf Callus Cultures of Decalepis hamiltonii Wight. \& Arn.}

\author{
Jacob George, Harsh Pal Bais, and G.A. Ravishankar ${ }^{1}$ \\ Plant Cell Biotechnology Department, Central Food Technological Research \\ Institute, Mysore 570 013, India
}

\section{P. Manilal}

\section{Planning, Monitoring and Coordination Department, Central Food} Technological Research Institute, Mysore 570 013, India

Additional index words. response surface methodology, regeneration, benzyladenine, napthaleneacetic acid, sucrose, swallow root, micropropagation

\begin{abstract}
Response surface methodology was utilized in statistical optimization of three quality factors (the number of multiple shoots, shoot length, and number of leaves) pertaining to regeneration of plantlets from leaf calli of Decalepis hamiltonii Wight. \& Arn. (swallow root). The variables evaluated were the levels of sucrose, $\mathrm{BA}$, and NAA each at two different concentrations. Response surfaces for shoot length and multiple shoot number were useful in achieving optimal levels of media constituents and in understanding their interactions, but response surfaces for number of leaves were not. The data indicate that sucrose, BA, and NAA levels may be manipulated to increase or decrease quality factors chosen. This approach may be useful in developing a micropropagation protocol for D. hamiltonii. Chemical names used: benzyladenine (BA); napthaleneacetic acid (NAA).
\end{abstract}

Response surface methodology (RSM) is an analytical tool to determine the optimum conditions for a multivariable system and has been applied for optimizing media for tissue culture (Myers, 1971). Both nutritional and hormonal factors play a crucial role in the growth and development of plants in vitro (George, 1996). The level of sucrose is a major factor, as are the nature, concentrations, and ratios of various endogenous and exogenous auxins and cytokinins.

In such studies, RSM (Dziezak, 1990) has been used to optimize the combinations of growth regulators and stage of maturity of fruit for callus initiation and development in Psidium guajava L. (Madhavi et al., 1992). RSM was used to analyze the interaction of hormones and polyamines in affecting the plating efficiency of protoplasts of Ipomoea batatas (L.) Poir. (Eiler et al., 1988), and to optimize the immobilization conditions for higher yields of capsaicinoids in Capsicum frutescens L. (Suvarnalatha et al., 1993).

Received for publication 7 May 1998. Accepted for publication 15 July 1999. J.G. and H.P.B. are thankful to the Council of Scientific and Industrial Research, New Delhi, for the senior research fellowship. This work was carried out with funding from the Dept. of Science and Technology (DST), Government of India (SP/SO/A/09/98). The cost of publishing this paper was defrayed in part by the payment of page charges. Under postal regulations, this paper therefore must be hereby marked advertisement solely to indicate this fact.

${ }^{1}$ To whom reprint requests should be addressed. Fax: +91-821-517233; E-mail: pcbt@ cscftri.ren.nic.in and sucrose in multiple shoot induction and to develop an efficient micropropagation system for Decalepis hamiltonii.

\section{Materials and Methods}

Source of explants. Healthy plants of Decalepis hamiltonii were collected from Gumballi forest ranges in BR hills, Mysore District, India.

Media and culture conditions. The medium was supplemented with BA and NAA for $D$. hamiltonii at prescribed concentrations as per the experimental design. The media ( 15 $\mathrm{mL})$ were prepared in test tubes $(60-\mathrm{mL}$ capacity) and the $\mathrm{pH}$ adjusted to $5.8 \pm 0.1$. Agaragar (HiMedia, Mumbai, India) was added at $0.8 \%(\mathrm{w} / \mathrm{v})$ as the gelling agent and homogenized by boiling, and the media were subsequently autoclaved at $1.2 \mathrm{~kg} \cdot \mathrm{cm}^{-2}$ for $20 \mathrm{~min}$. Leaf segments measuring 5-10 mm were surface-sterilized with mercuric chloride $(0.15 \%$ $\mathrm{w} / \mathrm{v})$ and transferred to the medium under aseptic conditions in a laminar airflow chamber. The cultures were maintained at a constant $25 \pm 2{ }^{\circ} \mathrm{C}$ under an 18-h photoperiod $\left(4.4117 \mathrm{~J} \cdot \mathrm{m}^{-2} \cdot \mathrm{s}^{-1}\right)$ provided by cool-white fluorescent lamps (four tubes, $122 \mathrm{~cm}, 40 \mathrm{~W}$ each, Phillips, India). Data on multiple shoot induction were recorded after $30 \mathrm{~d}$ of culture.

Multiple shoots were initiated from callus derived from the explants. After $30 \mathrm{~d}$ of culture the shoot cultures from the eight replicates of each treatment were analyzed for the number of shoots per explant, shoot length, and leaf number. The data obtained were subjected to Fisher's F test and (estimated coefficient of significance, $P \leq 0.05$ ) tested using Student's $t$ test (Steele and Torrie, 1980).

The response surface graphs were obtained from the regression equation, keeping the response function on the $\mathrm{Z}$ axis; the $\mathrm{X}$ and $\mathrm{Y}$ axes represent two independent variables, while the other variable is kept at a constant level.

Experimental design. An eight-point, full, two-way factorial design was used with three center points (i.e., three replicates used for estimation of variance) (Box et al., 1978; Nabais and Malcata, 1995) aimed at fitting the polynomial of the following form:

$$
\begin{aligned}
& y=b_{o}+\sum b_{i} x_{i}+\sum b_{i j} x_{i} x_{j}, \\
& i, j=1, n, i \neq j,
\end{aligned}
$$

where $b_{o}$ is the intercept, $b_{i}(i=1,2,3)$ are 
Table 1. Response surface design for $2 \times 2 \times 2$ factorial, plus three replicates of the centerpoint, giving observed $\left(\mathrm{O}^{\mathrm{b}}\right)$ and predicted $\left(\mathrm{P}^{\mathrm{a}}\right)$ values of the response for the fitted model.

\begin{tabular}{|c|c|c|c|c|c|c|c|c|c|c|}
\hline \multicolumn{2}{|r|}{$\begin{array}{c}\text { Sucrose (\%) } \\
\mathrm{X}_{1}\end{array}$} & $\begin{array}{c}\text { NAA } \\
\left(\mathrm{mg} \cdot \mathrm{L}^{-1}\right) \\
\mathrm{X}_{2}\end{array}$ & $\begin{array}{c}\mathrm{BA} \\
\left(\mathrm{mg} \cdot \mathrm{L}^{-1}\right) \\
\mathrm{X}_{3}\end{array}$ & \multicolumn{3}{|c|}{ Coded factors } & \multicolumn{2}{|c|}{$\begin{array}{l}\text { Shoot length } \\
(\mathrm{cm})\end{array}$} & \multicolumn{2}{|c|}{ Shoot no. } \\
\hline$\overline{1}$ & 1 & 0.05 & 0.05 & -1 & -1 & -1 & 5.452 & 5.58 & 2.3 & 2 \\
\hline 4 & 3 & 1.9 & 0.05 & 1 & 1 & -1 & 4.152 & 4.32 & 1.7 & 1.6 \\
\hline 5 & 1 & 0.05 & 1.9 & -1 & -1 & 1 & 6.474 & 6.26 & 4.0 & 3.6 \\
\hline 6 & 3 & 0.05 & 1.9 & 1 & -1 & 1 & 6.994 & 7.2 & 4.0 & 4.4 \\
\hline 9 & 2 & 0.97 & 0.97 & 0 & 0 & 0 & 5.43 & 4.48 & 2.65 & 2 \\
\hline 10 & 2 & 0.97 & 0.97 & 0 & 0 & 0 & 5.43 & 4.48 & 2.65 & 2.2 \\
\hline 11 & 2 & 0.97 & 0.97 & 0 & 0 & 0 & 5.43 & 4.54 & 2.65 & 2 \\
\hline
\end{tabular}

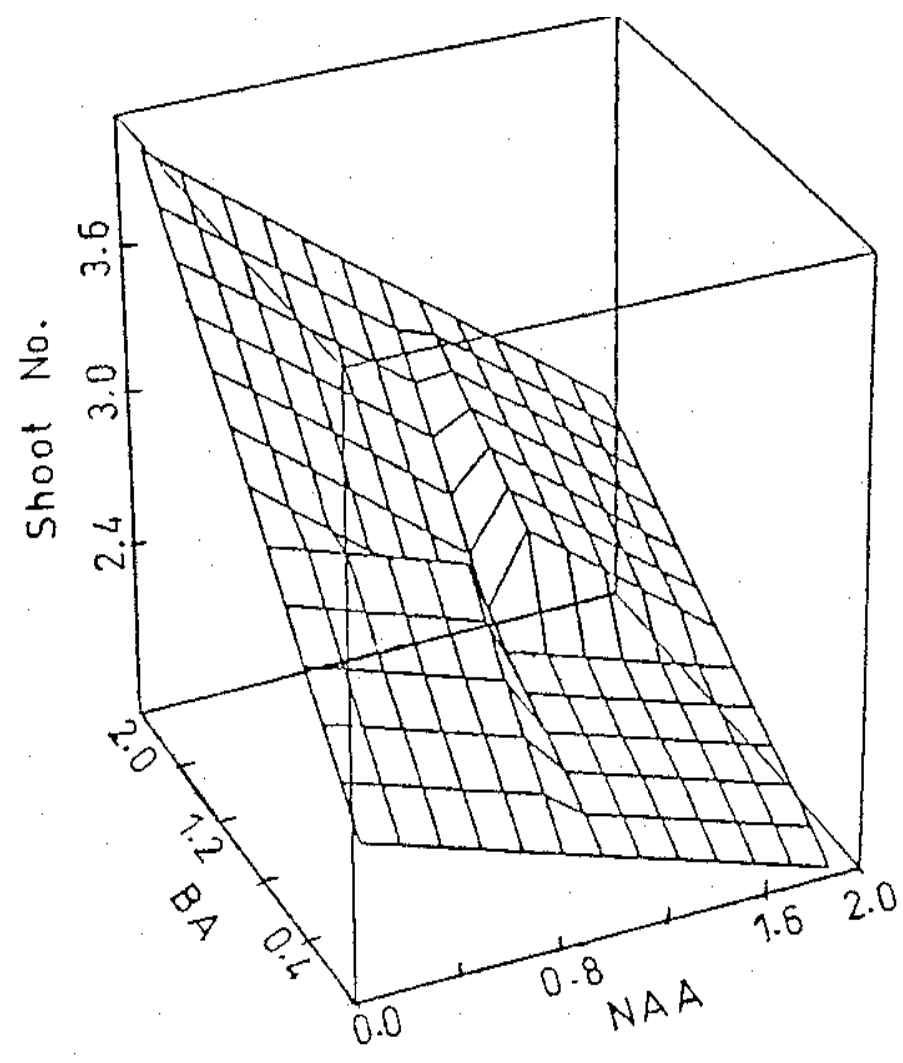

Fig. 2. Surface plot of shoot number in $D$. hamiltonii with variable concentrations of NAA and BA.
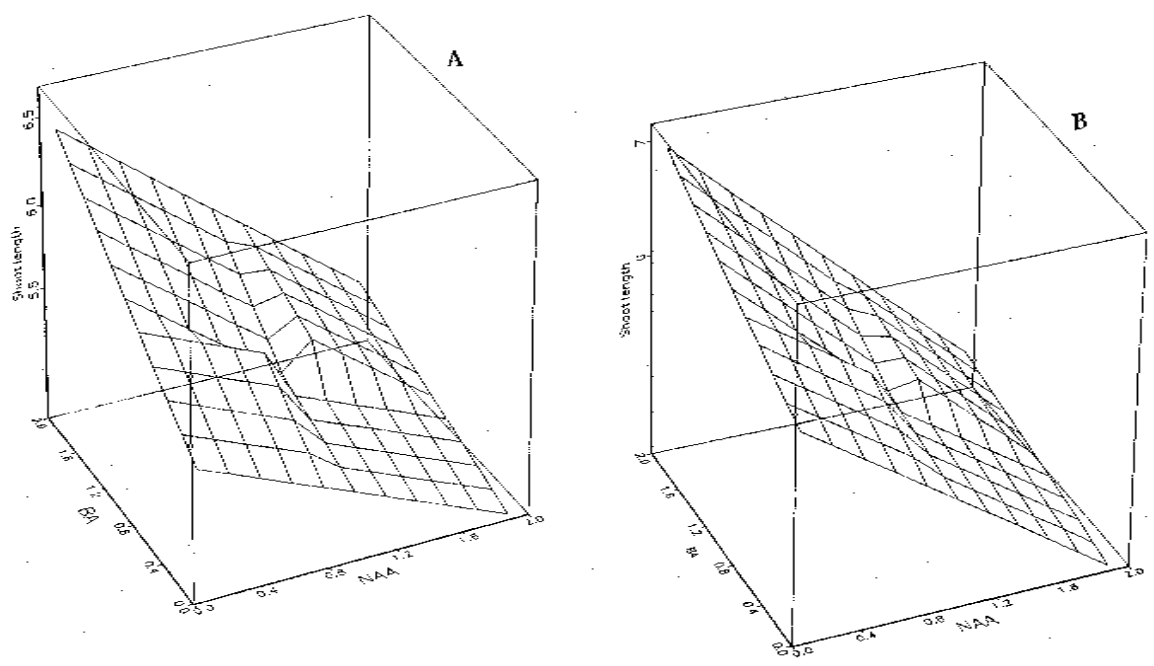

Fig. 3. Surface plot of shoot length in D. hamiltonii as affected by concentration of NAA and BA in media containing (A) $1 \%$ sucrose or (B) $3 \%$ sucrose. parameters associated with the linear terms in the model, $\mathrm{b}_{\mathrm{ij}}(\mathrm{i}, \mathrm{j}=1,2,3)$ are parameters associated with the cross-product terms, and $\mathrm{n}$ is the number of factors involved. The model was fitted using standard response surface methodology.

Three critical parameters known to influence the initiation and development of multiple shoots in D. hamiltonii were selected using two levels of each. The results obtained for the parameters are tabulated in Table 1. The model was designed with the assumption that initiation of multiple shoots from calli obtained from the leaf explants and their subsequent development are functions of its interacting factors, such as sucrose, BA, and NAA. The significance of the coefficients in the polynomial was tested against tabulated values ( $t$ test) as suggested by Akhanozarova and Kafarov (1978) and Fisher's F test for the validation of the model.

Optimization of the function was estimated using MS-X (Microsoft Corp., Redmond, Wash.) ver. 5.0 Solver modules. The maximizing steps with the constraints placed as the lowest and a highest coded value for each of the variables was carried out using a quasiNewton search algorithm.

\section{Results and Discussion}

The significance of the coefficients in the second-order polynomial was tested against the tabulated values using the $t$ test after validating the model (Akhanozarova and Kafarov, 1978). Increasing the concentration of NAA reduced shoot number (Fig. 2) while sucrose had no effect (data not shown). Maximum response was obtained when the NAA concentration was least $\left(0.05 \mathrm{mg} \cdot \mathrm{L}^{-1}\right)$ and the BA was maximum $\left(1.90 \mathrm{mg} \cdot \mathrm{L}^{-1}\right)$. Both responses were linear. The fitted model for the shoot number response is:

$y=2.65-0.5 X_{2}+0.65 X_{3}-0.2 X_{2} X_{3}$, where $X_{2}$ is the NAA level in $\mathrm{mg} \cdot \mathrm{L}^{-1}, \mathrm{X}_{3}$ is the BA level in $\mathrm{mg} \cdot \mathrm{L}^{-1}$, and $\mathrm{y}$ is the predicted shoot number. For evaluating shoot length, the fitted model for the response is:

$y=5.43-0.793 X_{2}+0.368 X_{3}-0.268 X_{1} X_{2}$ $-0.143 \mathrm{X}_{2} \mathrm{X}_{3}$, where $\mathrm{X}_{2}$ is the NAA level in $\mathrm{mg} \cdot \mathrm{L}^{-1}, \mathrm{X}_{3}$ is the BA level in $\mathrm{mg} \cdot \mathrm{L}^{-1}$, and $\mathrm{y}$ is the predicted shoot length.

In Fig. $3 \mathrm{~A}$ and $\mathrm{B}$ the concentration of sucrose was kept constant (lowest and highest, 
Table 2. Decision table showing optimum conditions for shoot length.

\begin{tabular}{lcccc}
\hline \hline Sl. no. & $\begin{array}{c}\text { Sucrose }(\%) \\
\left(\mathrm{X}_{1}\right)\end{array}$ & $\begin{array}{c}\mathrm{NAA}\left(\mathrm{mg} \cdot \mathrm{L}^{-1}\right) \\
\left(\mathrm{X}_{2}\right)\end{array}$ & $\begin{array}{c}\mathrm{BA}\left(\mathrm{mg} \cdot \mathrm{L}^{-1}\right) \\
\left(\mathrm{X}_{3}\right)\end{array}$ & $\begin{array}{c}\text { Maximum shoot } \\
\text { length }(\mathrm{cm})\end{array}$ \\
\hline (i) & 1 & 0.05 & 1.9 & 6.47 \\
(ii) & 3 & 0.05 & 1.9 & 6.99 \\
(iii) & 3 & 0.05 & 0.05 & 5.97 \\
(iv) & 1 & 1.9 & 1.9 & 5.12 \\
\hline
\end{tabular}

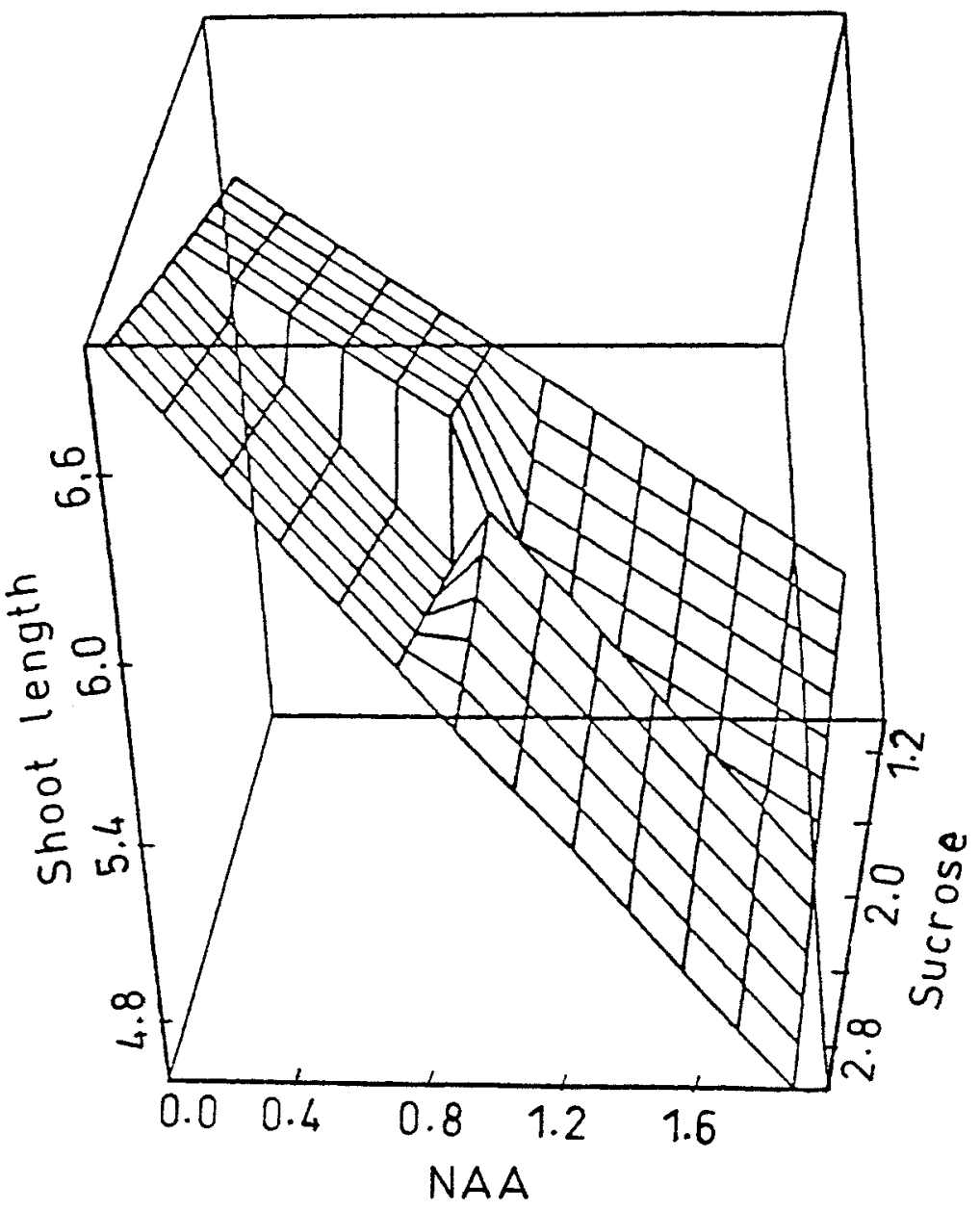

Fig. 4. Surface plot of shoot length in D. hamiltonii with maximum concentration of BAP $\left(1.9 \mathrm{mg} \cdot \mathrm{L}^{-1}\right)$.
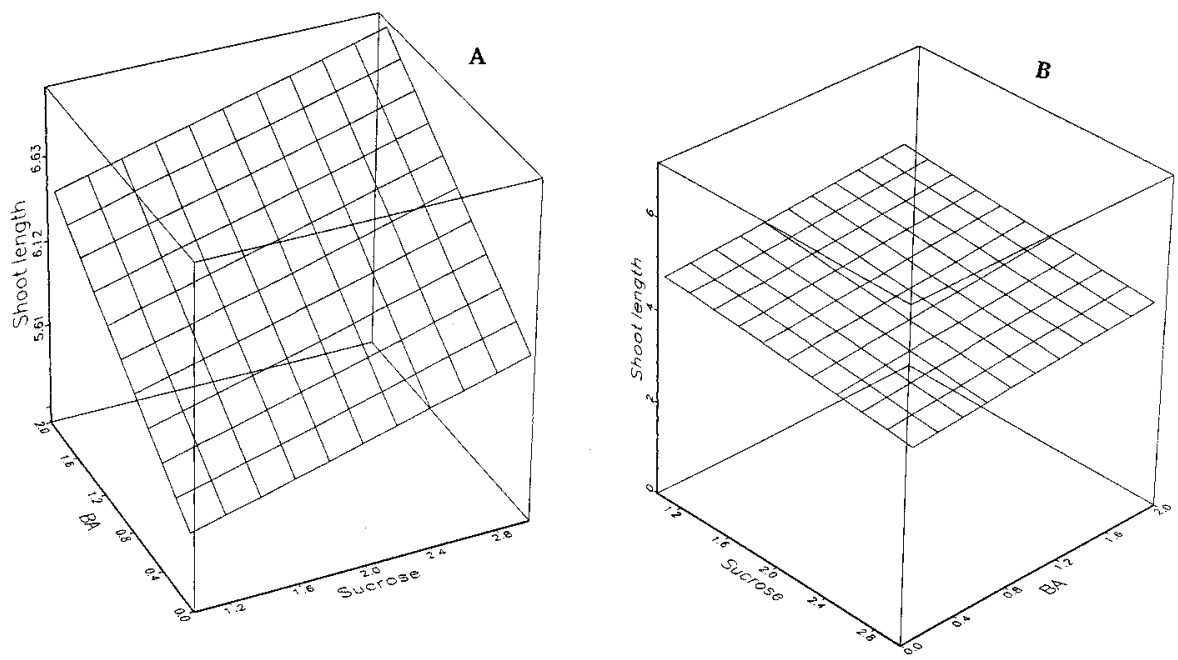

Fig. 5. Surface plot of shoot length in D. hamiltonii as affected by concentrations of BA and sucrose in media containing NAA at (A) $0.05 \mathrm{mg} \cdot \mathrm{L}^{-1}$ or $\left(\right.$ B) $1.9 \mathrm{mg} \cdot \mathrm{L}^{-1}$. respectively) while the other two factors varied. When the sucrose concentration was least, the maximum shoot length was $6.474 \mathrm{~cm}$; when the concentration was highest, maximum shoot length was $6.994 \mathrm{~cm}$. In both cases, as the equations indicate, a lower concentration of NAA coupled with a higher concentration of BAP favored increased shoot numbers (Table 2). Thus, higher sucrose levels $(3 \%)$ together with maximum BA $(1.9$ $\left.\mathrm{mg} \cdot \mathrm{L}^{-1}\right)$ and minimum NAA $\left(0.05 \mathrm{mg} \cdot \mathrm{L}^{-1}\right)$ resulted in maximum shoot length. One may infer that the interaction of sucrose with NAA was the decisive factor that determined shoot length.

When BAP levels were maximal and other factors varied, maximum shoot length was obtained when the concentrations of NAA and BA were 0.05 and $1.9 \mathrm{mg} \cdot \mathrm{L}^{-1}$, respectively (Fig. 4). Irrespective of varying conditions, the predictive values were in the range of 5-7.

When NAA level was lowest and other factors were variable, i.e., increased sucrose concentration at $3 \%$ and fixed value of BA at $0.05 \mathrm{mg} \cdot \mathrm{L}^{-1}$, the range of predictive values was 5.5 to 7 (Fig. 5A).

When NAA level was highest and the other factors were variable, maximum shoot length was $5.122 \mathrm{~cm}$ with minimal sucrose and maximal BA concentrations (Fig. 5B).

The optimum combination of concentrations of BA and NAA was 1.9 and $0.05 \mathrm{mg} \cdot \mathrm{L}^{-1}$, respectively. Shoot number exhibited a positive linear relationship with BA concentration and was maximum at the highest levels of BA. However, the increase in shoot number was evident in clusters of short shoots. Maximum shoot length was obtained when sucrose concentration was $3 \%$, NAA concentration minimum $\left(0.05 \mathrm{mg} \cdot \mathrm{L}^{-1}\right)$, and BA concentration maximum $\left(1.9 \mathrm{mg} \cdot \mathrm{L}^{-1}\right)$ (Table 3$)$. This showed the positive effect of BA on shoot length and shoot multiplication, and justifies exclusion of NAA in later stages. However, the same concentrations of the two hormones and sucrose did not effect the number of leaves.

Our emphasis on the number and length of shoots developed from the leaf callus is of significance, since a good multiplication rate is the most important factor in rendering a propagation protocol cost-effective. The optimum combination of factors obtained by using the methodology has been effective in developing an efficient micropropagation protocol for $D$. hamiltonii.

\section{Literature Cited}

Akhanozarova, S. and V. Kafarov. 1978. Experimental optimization in chemistry and chemical engineering. Mir Publishers, Moscow.

Box, G.E.P. 1954. The exploration and exploitation of response surfaces. Some general considerations and examples, p. 16-55. In: J.A. Nelders and R.A Mead (eds.). Principles and procedures of statistics. MacGraw-Hill, New York.

Cochran, W.G. and G.M. Cox. 1963. Some methods for the study of response surfaces. Experimental design. $2^{\text {nd }}$ ed. Asia Publishing House, New Delhi.

Dziezak, J.D. 1990. Taking the gamble out of product development. Food Technol. 6:117.

HortSCIEnCE, Vol. 35(2), April 2000 
Table 3. Effect of concentration of constant parameter and varying factors with observed response range (shoot length).

\begin{tabular}{|c|c|c|c|c|}
\hline Constant & $\begin{array}{l}\text { Concn } \\
\left(\mathrm{mg} \cdot \mathrm{L}^{-1}\right)\end{array}$ & $\begin{array}{l}\text { Varying } \\
\text { factors }\end{array}$ & $\begin{array}{l}\text { Observed } \\
\text { response range } \\
(\mathrm{cm})\end{array}$ & $\begin{array}{c}\text { Percentage increase in } \\
\text { shoot length of } \\
\text { highest means } \\
\text { minus lowest } \\
\text { observed value }\end{array}$ \\
\hline Sucrose & 10,000 & NAA, BA & $5.12-6.47$ & 26.4 \\
\hline Sucrose & 30,000 & NAA, BA & $4.60-6.99$ & 52 \\
\hline BA & 1.9 & Sucrose, NAA & $4.60-6.99$ & 52 \\
\hline NAA & 0.05 & Sucrose, BA & $5.45-6.99$ & 28.3 \\
\hline NAA & 1.9 & Sucrose, BA & $4.15-5.12$ & 23.4 \\
\hline
\end{tabular}

Eliers, R.J., J.G. Sullivan, and R.M. Skirvin. 1988. Analyzing the effects of exogenous polyamines and growth regulators on plating efficiency of sweet potato protoplasts using a central composite test design. Plant Cell Rep. 7:216-219.

George, E.F. 1996. Plant propagation by tissue culture. Part II. In practice. $2^{\text {nd }}$ ed. Exegetics Ltd., Baringstoke, England.

Madhavi, D.L., R. Nagin Chand, D. Rajalakshmi, and M.V. Patwardhan. 1992. Effects of growth hormones and maturity of fruits on the callus cultures of Guava (Psidium guajava) fruits using response surface methodology. J. Sci. Food and Agr. 58:29-34.

Myers, R.H. 1971. Response surface methodology. Allyn and Bacon, Boston.

Nabais, R.M. and F.X. Malcata. 1995. Optimizing a lactic fermentation of sliced carrots. J. Food Process. Preserv. 19:427-449.

Steele, R.D. and J.H. Torrie. 1980. Principles and procedures of statistics. MacGraw-Hill, New York.

Suvarnalatha, G., R. Nagin Chand, G.A. Ravishankar, and L.V. Venkataraman. 1993. Computer aided modelling and optimization for capsaicinoid production by immobilized Capsicum frutescens cells. Enzyme Microbiol. Tech. 15:710-715. 